\title{
Management of Knowledge Workers*
}

\author{
Hans K. Hvide and Eirik Gaard Kristiansen ${ }^{\dagger}$
}

January 26, 2011

\begin{abstract}
We study how firm-specific complementary assets and intellectual property rights affect the management of knowledge workers. The main results show when a firm will wish to sue workers that leave with innovative ideas, and the effects of complementary assets on wages and on worker initiative. We argue that firms protected weakly by complementary assets must sue leaving workers in order to obtain positive profits. Moreover, firms with more complementary assets pay higher wages and have lower turnover, but the higher pay has a detrimental effect on worker initiative. Finally, our analysis suggests that strengthening firms' property rights protection reduces turnover costs but weakens worker initiative.
\end{abstract}

Keywords: entrepreneurship, innovation, intellectual property rights, litigation, personnel economics, R\&D, start-ups, worker mobility.

${ }^{*}$ We thank an anonymous referee, Amar Bhide, Patrick Bolton, Michael Katz, Eddie Lazear, Josh Lerner, Lasse Lien, Jim March, and Suzanne Scotchmer for helpful comments. Support for this project from the Norwegian Research Council (KUNI program) is also gratefully acknowledged.

${ }^{\dagger}$ Hvide: University of Aberdeen, Business School. Kristiansen: Norwegian School of Economics and Business Administration (NHH). Hvide is also affiliated with CEPR and NHH. 


\section{Introduction}

Knowledge workers make up a significant proportion of advanced economies' workforces. ${ }^{1}$ Their expertise is important for countless organizations around the world, but still we have limited insight into how firms manage such workers. The available evidence suggests that firms use two main instruments to incentivize and retain knowledge workers: wage and litigation policies. For example, Fisk (2001) gives a fascinating historical account of how Du Pont, the explosives/chemistry company, used wage policy to make workers stay and aggressive litigation against workers who left to protect knowledge that was vital to the company.

This paper studies the management of knowledge workers in an environment where remuneration contracts are incomplete and worker initiative stems from the possibility of leaving the employer carrying valuable ideas. Our analysis addresses two questions. When will the firm take legal action and sue departing knowledge workers? And how do firm-specific complementary assets and property rights protection determine a firm's wage policy vis-a-vis knowledge workers? The existing literature examines how complementary assets can prevent competitors from expropriating a firm's intellectual property. ${ }^{2}$ We study how such assets can be used in combination with wage and suing policies to prevent employees from leaving with valuable ideas.

The crux of the paper is twofold. First, regarding suing policy, a worker that expects the firm to sue has weaker incentives to exert effort, because the fraction of the surplus that is accrued by a leaving worker decreases. The firm's litigation policy therefore balances the costs of having less motivated workers with the benefits of fewer workers departing. We find that a firm protected strongly by formal property rights may not sue departing workers. The reason is that suing would then be a "too powerful" instrument and ruin worker initiative. In contrast, we find that a firm not protected by complementary assets must sue in order to achieve positive profits. The intuition is that if the firm does not have complementary assets, not suing will lead to adverse selection, where only workers

\footnotetext{
${ }^{1}$ Some estimates are as high as 25-30 percent. See the January 2006 survey of the Economist, Roberts (2004), or Neef (1999) for evidence on the importance of knowledge workers.

${ }^{2}$ See the seminal contributions of Mansfield (1986) and Teece (1986) on how firm-specific complementarities can protect intellectual property in the absence of legal protection.
} 
with low-value ideas stay on in the firm. Second, regarding wage policy, we argue that firms with more complementary assets should pay higher wages but will consequently experience less worker initiative. The intuition is that a firm with more complementary assets has a higher marginal value from workers staying on, and will therefore pay higher wages in order to keep more workers. However, such higher pay will serve as a cushion that weakens worker initiative.

In the model, firms are exposed both to moral hazard, in that workers exert unobservable effort to generate ideas, and to adverse selection, in that workers observe their ideas privately. After a worker has generated an idea, whose value is private information to the worker, the firm offers a continuation wage that the worker may accept and stay on in the firm, or reject and start up his own business based on the idea. If the worker starts up a business, the firm may litigate against the worker. Complementary assets inside the firm play a role in determining how valuable the idea is to the firm. The legal environment plays a role in determining how likely it is that the firm will win a case against the worker.

In our benchmark analysis, the complete contract case, the use of complementary assets is contractible, and the worker can be rewarded based on the profit generated by the idea. We show that such complete contracts imply that the firm-specific assets are always used efficiently, worker effort is high, and the worker never leaves the firm.

In our main analysis we deviate from the benchmark by assuming that the use of firm-specific complementary assets is noncontractible. The incomplete contracts case is realistic because of the ex-ante costs associated with writing complete contracts on contingent use of complementary assets (Williamson, 1975) and the ex-post difficulties in verifying the value of the idea when firm-specific assets have been used (Aghion and Tirole, 1994). Noncontractibility in the use of complementary assets implies that profit sharing between the worker and the firm is not feasible, and that the firm can only offer a fixed-wage contract to the worker.

We explore the incomplete-contract case in two directions. First, we investigate wage and litigation policies when the firm cannot commit to wage and litigation policies at the time the worker is hired. We imagine a firm that has not established a reputation for how it will act when workers leave with ideas and for how it will reward workers developing new ideas. A reputation for rewarding ideas and not suing leaving workers is difficult 
to establish when wages are secret or workers develop valuable ideas infrequently. We also analyze the case where reputation for or commitment to wage and suing policies is feasible.

In the incomplete contracts case, profit sharing inside the firm is not feasible, and a worker's only motivation to exert effort stems from being able to capture a fraction of the value of the idea if leaving. We find that a firm more strongly protected by complementarities pays higher wages, has less turnover, and has less motivated workers. Stronger complementarities imply that a given idea has a higher value inside the firm, and the firm decreases turnover by paying more. Paying more implies less motivated workers, because the entrepreneurial option becomes less attractive relative to staying on in the firm. The available evidence, discussed in Section 5, gives some support to these predictions.

A worker that expects the firm to sue has weaker incentives to exert effort, because the value of the entrepreneurial option decreases. The firm's litigation policy therefore balances the costs of having less motivated workers with the benefits of fewer workers departing. At a casual level, this trade-off accords with the personnel policy at HewlettPackard, which in addition to encouraging workers to start up their own companies had a reputation for employees being highly motivated. We find that a firm strongly protected by formal property rights may not sue leaving workers, in order to induce high effort. In contrast, we find that a firm not protected by complementary assets must sue in order to achieve positive profits, the reason being that not suing will lead to only workers with low-value ideas stay on in the firm.

\subsection{Related literature}

A range of evidence supports the idea that knowledge workers leaving pose a threat to firms. For example, Groysberg et al. (2001) find that equity analysts, particularly "stars", quite commonly leave and start up their own companies. Bhide (2000) finds that $71 \%$ of entrepreneurs in a sample of fast-growing companies replicated or modified an idea encountered through previous employment, which echoes earlier findings by Cooper (1985) and by Delaney (1993). Oyer and Schaefer (2005) and Møen (2005) find evidence 
consistent with firms using their wage policy to retain workers.

On litigation of employees, Stone (2002) reports that the number of court cases involving covenants not to compete and trade secrets has increased sharply in recent decades. Similar findings are reported by Lowry (1988). Case evidence suggests heterogeneity in the litigation policy of R\&D-intensive firms. Starting with the famous trade secret case E.L. du Pont de Nemours Powder Co. v. Masland in 1914, there are many examples of firms that have sued departing workers. Hewlett-Packard institutionalized a famous policy where workers were encouraged to leave and start up their own companies, often with ideas gained from their employment at Hewlett-Packard. ${ }^{3}$ Similarly, Google is reputed to be lenient with departing employees. In a much-publicized recent case, workers from the electronics company Cadence founded a company, Avant!, based on software programs and customer relations developed at Cadence. Cadence sued the departing workers. Several of the workers received fines and prison sentences (Glynn and Mukherjee, 2003) and were also required to pay a restitution fee. Intel and Microsoft have a reputation for being uncooperative with leavers, and the same holds for a range of Route 128 companies, as described by Saxenian (1994). ${ }^{4}$

There are three branches of the theoretical economics literature that address issues that are related to the current paper: the management of innovation, the economics of litigation, and the industrial economics of research and development (R\&D). This paper differs from the existing literature in several important respects.

Pakes and Nitzan (1983) consider a moral hazard problem where firms have no formal property rights protection and workers can appropriate part of their output. Such appropriation provides workers with an incentive to provide effort. While our model

\footnotetext{
${ }^{3}$ The response of Dave Packard, one of the two founders of Hewlett-Packard, was, "Are we upset that they left us? On the contrary, Bill and I understand and respect their entrepreneurial spirit" (Packard, 1995).

${ }^{4}$ Gompers and Lerner (1998) discuss an interesting case of the trade-offs involved in deciding whether to sue leavers or not. Xerox set up a committee among whose duties was to decide upon how to prevent technology leakage from the firm. "The committee focused on two options: (1) to begin aggressively litigating those who try to leave with new technologies, and (2) to invest in people trying to leave Xerox. Variations in employee noncompetition law across states (and particularly the weak level of protection afforded by the California courts) make it unclear how effective a policy of aggressive litigation would be. Furthermore, such a policy might reduce Xerox's ability to recruit the best research personnel, who might not want to limit their future mobility. Based on the committee's recommendation, [Xerox] Chairman Kearns decided to pursue a corporate venture capital program."
} 
shares this feature of Pakes and Nitzan, their paper does not consider workers having private information about output, which drives turnover in our model; nor does it consider the possibility of firms litigating against departing workers. ${ }^{5}$ In the incomplete contract setting of Aghion and Tirole (1994), the problem is how to allocate ownership of innovations to alleviate holdup problems between a research unit and a customer. We consider incomplete contracts between a worker (innovator) and the firm related to access to firmspecific complementary assets. Similar to Aghion and Tirole (1994), incomplete contracts and holdup problems result in inefficient use of complementary assets and prevent use of profit-sharing contracts between the worker and the firm.

Hellmann (2007) and Subramanian (2005) consider the multitasking problem that ensues if a worker can engage in "private activities" on the job with the intention of creating a start-up later. In contrast to these papers, we assume that the main problem from the firm's viewpoint is that workers leave with ideas generated through their legitimate work. Neither of these papers discusses the firm's incentives to litigate against workers. Gambardella and Panico (2008) consider how firms can offer a menu of contracts describing job autonomy, wage, and how worker time is split between innovative and less innovative activities in order to attract talented workers. In contrast to their paper, which considers the hiring of workers with unobservable talent, we examine how a firm should motivate workers to produce new ideas (unobservable worker effort). Both models predict that the best workers leave in equilibrium. ${ }^{6}$

In Anton and Yao (1995), a worker discovers an idea privately, and the authors study when the worker will leave the firm in order to develop the idea (start-up) and when the worker together with the firm will develop the idea (spin-off). A worker leaves if he would be in a weak bargaining position by staying and sharing the idea with the firm.

\footnotetext{
${ }^{5}$ The same holds for Kim and Marschke (2005). Hvide (2009) considers a model where workers have private information about the value of their ideas but does not consider workers' decisions about how much of an effort to make, or firms' suing decisions.

${ }^{6}$ Motta and Rønde (2003) analyze how noncompete clauses influence the worker's provision of innovative effort. They show that a firm might prefer not to include such a covenant in the employment contract, in order to commit to reward the worker. In contrast to our paper, they do not consider how the firm's behavior might be affected by the strength of property rights protection or by complementary assets. Lewis and Yao (2003) show that firms may choose an open research arrangement (open interaction with agents outside the firm) if this helps the firm in attracting workers. They do not consider workers' incentives to exert effort.
} 
As in our analysis, Anton and Yao (1995) analyze a setting where weak property rights restrict the firm's ability to compensate the worker for ideas, which may lead to startup activities. In our model, ex-post holdup problems associated with transfer pricing of firm-specific complementary assets prevent credible profit-sharing contracts. Furthermore, Anton and Yao (1995) do not explore the role of complementary assets on the firm's wage and litigation policies.

Anton and Yao $(1994,2002)$ ask how a privately informed inventor might sell an idea when formal property rights are nonexistent. Anton and Yao (1994) argue that the threat of selling off the idea to a competitor may give the inventor bargaining power with an incumbent firm, and Anton and Yao (2002) argue that the innovator may partially disclose the idea and can then persuade the firm to pay more. ${ }^{7}$ We use the insight from Anton and Yao that an inventor may be reluctant to reveal the content of an idea to motivate our assumption that workers have private information about their innovations.

The incentives to litigate have been studied by several authors, e.g., Bebchuk (1984) and Reinganum and Wilde (1986) on pretrial negotiations, and Priest and Klein (1984) on the probability of succeeding in court. Cooter and Rubinfeld (1989) provide a review of this literature. Regarding empirical evidence, Siegelman and Waldfogel (1996) and Lanjouw and Lerner (1998) estimate a Priest-Klein model on data from litigation cases and find that intellectual property rights cases are relatively predictable but also quite hard to win (about 35\% are ruled in favor of the plaintiff in the former sample).

According to Mansfield (1986) and Teece (1986), in many industries, firms regard complementary assets, rather than intellectual property rights, as their main tool for protecting their innovations. By refusing access to firm-specific complementary assets, the firm makes it less tempting to steal intellectual property. This paper is to our knowledge the first on how complementary assets affect the management of knowledge workers. Most of the industrial economics literature on $R \& D$ has considered the firm as a unit and examined how product-market competition and patent policy determine R\&D investments jointly (for a comprehensive overview, see Scotchmer, 2004). While this literature provides

\footnotetext{
${ }^{7} \mathrm{~A}$ related literature considers how to protect innovations from product-market competitors (see e.g., Anton and Yao, 2004). The underlying tension is that patents may give stronger formal rights but also disclose more about the innovation.
} 
insight into how a firm's competitive environment stimulates investments in R\&D, it has not analyzed how successful innovation depends on worker initiative and the firm's personnel policy.

The paper is structured as follows. The model is presented in Section 2. Section 3 establishes the benchmark case with complete contracts on firm-specific complementary assets. Sections 4 and 5 analyze our main case with incomplete contracts. Section 4 contains the noncommitment analysis, while Section 5 contains the commitment analysis. The empirical implications of the model are discussed in Section 6. Section 7 examines the possibility of profit-sharing arrangements with workers and out-of-court settlements. Section 8 concludes.

\section{The model}

The model describes the development of an idea inside the firm by a worker and how the firm can motivate the worker and at the same time benefit from new ideas. There are five dates in the model.

Date 1: There is one principal (firm) and one agent (worker). The agent has no private wealth, and reservation utility $\bar{U}>0$. At date 1 , the agent is hired and paid an initial wage $F \geq 0 .{ }^{8}$ The worker then exerts effort $e$ at a private cost $c(e)$, where $c(e)$ satisfies $c(0)=c^{\prime}(0)=0$ and $c^{\prime \prime}(e)>0$.

Date 2: The worker's effort produces an idea with stand-alone value $x$, where $x=e+\epsilon$, and $\epsilon$ is a random variable with full support and distribution function $G(\epsilon) .{ }^{9}$ Throughout, we assume for simplicity that $G(\epsilon)$ is such that the utility and profits functions are concave globally. The agent learns $x$, whereas the firm learns $x$ with probability $p$. In the main analysis we let $p=0$, so that the worker has private information about $x$. In Section 7.1 we discuss the case where $p>0$.

\footnotetext{
${ }^{8} F=0$ reflects the case where the firm pays the worker a low wage in the first period (although not a negative wage, which would violate limited liability), but the worker has the chance of discovering a valuable innovation.

${ }^{9}$ We assume that ideas with negative values are also implemented. All of our results continue to hold if we assume that ideas with negative values are scrapped, or that the support of $\epsilon$ is positive (so that all ideas have positive value).
} 
Access to firm-specific complementary assets increases the idea value from $x$ to $\theta x$, where $\theta \geq 1$. Weak complementarities correspond to $\theta$ close to 1 , and strong complementarities correspond to $\theta>>1$.

Date 3: The firm offers a continuation wage $B$ to the worker. In Section 4 , we consider the benchmark where the firm can make the continuation wage a function of profits when firm-specific complementary assets are employed, i.e., contracts are complete. In Sections 5 and 6 we consider the incomplete contracting case, where the firm can only make the wage depend credibly on profit if complementary assets are not employed.

Date 4: If the wage offer is accepted by the worker, the firm's payoff is $\theta x-B$ and the worker's payoff is $B$. If the contract offered at date 3 is rejected by the worker, he quits the firm and develops a start-up based on the idea value $x$. If the worker leaves, the firm chooses whether to litigate against the worker or not. If the firm does not sue, the final payoffs become 0 to the firm and $x$ to the worker.

Date 5: If the firm sues, the payoffs depend on the court outcome. Upon reaching the court, the idea has matured into something more "physical" (such as technical drawings or a prototype) that - although its value is not verifiable - the court can transfer from the worker to the firm. The court rules in favor of either the firm or the worker. If the court rules in favor of the firm, the firm gets $\theta x$. The worker gets 0 . In contrast, if the court rules in favor of the worker, the worker keeps the idea and develops it independently of the firm. The firm then gets 0 , and the worker gets $x$. We assume that the litigation costs are zero. In Section 7.2 we analyze the implications of positive suing costs.

As evidenced by a large body of legal literature (see Merges, 1999, or Kim and Marschke, 2005, p. 299, for references) firms and employees cannot contract easily around the problem of workers leaving with innovations, an important reason being that overly broad noncompete or "trailer" clauses will be voided by courts. We assume that enforcement by courts is probabilistic, in that the firm wins the litigation trial with probability $\phi \in[0,1]$. A high $\phi$ corresponds to the case where the court enforcement is strong. The idea that court outcomes are probabilistic is common in the theoretical literature (e.g., Cooter and Rubinfeld, 1989) and has substantial empirical support, see e.g., Lemley and Shapiro (2005). In the current context, one reason why court outcomes can be modeled most plausibly as probabilistic is that it can be difficult for courts to establish whether 
the innovation was conceived when the leaver was still an employee (Merges, 1999). ${ }^{10}$ We think of $\phi$ as partly being determined by industry characteristics such as difficulty in assessing the nature of early-stage innovations, and partly by legislation and practice.

An overview of the timing appears in Figure 1:

$\begin{array}{llllll}\text { Date } 0 & \text { Date } 1 & \text { Date } 2 & \text { Date } 3 & \text { Date } 4 & \text { Date } 5\end{array}$

$\begin{array}{llllll}\text { If possible, the } & \text { A worker is } & \text { The worker } & \text { The firm } & \text { If the worker } & \text { If the firm } \\ \text { firm commits } & \text { hired and } & \text { generates an } & \text { makes a wage } & \text { leaves, the } & \text { litigates, the } \\ \text { to wage and } & \text { chooses a non- } & \text { idea and } & \text { offer and the } & \text { firm decides } & \text { court makes } \\ \text { litigation } & \text { observable } & \text { learns its } & \text { worker accepts } & \text { whether to } & \text { a decision. } \\ \text { policies. } & \text { effort level. } & \text { value. } & \text { or rejects. } & \text { sue or not. }\end{array}$

Figure 1: Timing

In our main case, analyzed in Section 4, we assume that the firm cannot commit to litigation and wage policies at date 0 . For instance, it might be difficult to establish a reputation for a wage policy if wage levels are difficult to observe for outside workers, or it might be difficult to establish a reputation for not litigating against departing workers if they leave infrequently. Alternatively, the firm could be too young to have established a reputation. ${ }^{11}$ To understand the role played by the noncommitment assumption, in Section 5 we analyze a setting where commitment to wage and suing policies is feasible at date 0 .

The basic trade-offs in the main analysis are as follows. The worker chooses an effort level trading off its private cost against a higher value of the idea if he becomes an

\footnotetext{
${ }^{10}$ For example, Merges (1999, p. 49) reports that "... in Koehring Co. v. E.D. Etnyre $\mathscr{E}$ Co., an employee signed a fairly typical agreement requiring him to disclose all improvements, discoveries, and inventions related to business carried on or contemplated by his employer firm that he developed during employment. The court, stating that the agreement did not give an employer 'a mortgage on all thoughts occurring to the employee' and did not include ideas drawn from the employee's general knowledge, ruled that the employee's rough sketches and designs 'were never developed [during employment] to the extent that they constituted material subject to the agreement.'"

${ }^{11}$ Merges (1999, p. 43) discusses both the verifiability problem with early-stage innovations and the problems a firm might have in building a reputation. See Mailath and Samuelson (2006) for an extensive analysis of how firms might build a reputation in repeated relationships.
} 
entrepreneur. The firm sets a wage that trades off the gains from keeping better worker types (ideas) with the cost of paying more for all staying workers. We focus on perfect Bayesian equilibria (PBE). A combination of strategies is a PBE if three conditions are satisfied: the firm sets its wage and litigation policies optimally given its beliefs about worker behavior; the worker anticipates the firm's behavior and chooses his effort level and whether or not to leave to maximize his utility; and the firm's conjecture about the worker's behavior is fulfilled.

The model captures in a simple way how firm-specific complementary assets and the legal institutional framework affect the interaction between knowledge workers and employers. Several aspects of the legal process are left out of the model. For example, our model does not take into account that the court may demand that compensation be paid by the worker to the firm, rather than demanding that the idea be returned to the firm. Furthermore, in our basic model, the parties have no litigation costs. This LAST possibility is discussed in Section 7.2.

\section{Benchmark: complete contracts}

If the idea is developed inside the firm, firm-specific complementary assets can be employed. Such assets include patents, co-workers, production equipment, and technology. In the main analysis, we assume that using such assets increases production efficiency (by the factor $\theta$ ) but at the same time makes it impossible to write contracts on the marginal contribution of the worker. To understand the role played by the latter assumption, we now consider the benchmark case where the use of complementary assets does not prevent the firm from paying a wage conditional on profit.

The worker stays only if $B(x) \geq(1-\phi) x$. If the worker stays, the firm's profits equal $(\theta x-B)$. The firm chooses a wage $B(x)$ to maximize profits. We then have the following result.

Proposition 1 Suppose that the worker can be rewarded based on the profit generated by the idea. Then the firm offers the worker a wage equal to the entrepreneurial option, $(1-\phi) x$. There is no turnover, and firm profits are $(\theta+\phi-1) x$. 
The optimal contract ensures that the worker stays in the firm and uses the complementary assets to develop the idea. The worker receives no information rent additional to the outside value of the idea, and the firm maximizes profit by using firm-specific complementary assets efficiently. The optimal allocation of payoffs can be implemented by giving the worker a fixed share in the project outcome. The worker gets a share $s$ of profits, where $s=\frac{(1-\phi) x}{\theta x}=(1-\phi) / \theta$. The worker's continuation wage is associated positively with idea quality, and consequently there is profit sharing under complete contracts. ${ }^{12}$

\section{Incomplete contracts}

Firm-specific assets do not have a market price, and it is difficult to know in advance which assets will contribute to the development of the idea. Ex-post negotiation of specialized assets (such as licensing of patents) blurs the picture of the profitability of the idea and makes it difficult to write contracts based on profitability (for a similar idea, see e.g., Aghion and Tirole, 1994). For example, in the absence of comparable market prices, the firm may hold up the worker and tunnel profit out of the unit by charging high transfer prices for inputs. ${ }^{13}$ Hence, we assume that it is infeasible to write contracts based on profit if complementary assets are used and internally priced within the firm. We also assume that the worker cannot communicate credibly the true value of the idea to the firm, because a report would be cheap talk and cannot be verified. ${ }^{14}$ The combination

\footnotetext{
${ }^{12}$ If the firm can commit to wage and suing policies, the optimal contract may entail that the firm offers a larger share than $s$ in order to induce greater effort. It would be particularly important to induce effort if the outside option is small compared with the inside value of the idea ( $\phi$ close to 1 and $\theta$ large).

${ }^{13}$ If the firm is free to charge price $p$ for complementary assets, it can simply charge a sufficiently large price to make the profit of the separate unit, $\theta x-p$, zero. Outsiders can only observe the aggregate $\theta x-p$ and not observe whether low profit is because of a low $x$ or high $p$. Under complete contracts, the price $p$ can be decided at date 3 to prevent any subsequent holdup problems and bargaining over transfer prices.

${ }^{14}$ Anton and Yao $(1994,2002)$ examine how innovators should strategically reveal verifiable information to extract rent for his innovation. In both papers, the innovator needs either to have wealth (that can be used to signal credibly the value of the idea) or to benefit from having competing buyers of the idea (he can threaten to sell the idea to a competitor in order to reduce the holdup problem). In our case, the worker has no wealth to signal idea quality, and the only alternative use of the idea is to develop it on his/her own (without access to complementary assets). Merges (1999) cites an interesting empirical study of the commitment problem regarding workers with new ideas. Barry Weinmann and Brian D. Wright examined 879 idea submissions made to members of the National Association of Suggestion Systems. The study concludes that the suggestion box systems do elicit extra ideas from employees, but that compensation for ideas falls below the level that might be expected.
} 
of incomplete contracts and relationship-specific investments by firms and workers relates our analysis closely to seminal work by Williamson (1975) and later formal models by Grossman and Hart (1986) and Hart and Moore (1990). The observation made in the previous section - that complete contracts could prevent holdup problems and induce efficient investments - was made previously by Crawford (1988).

We assume that the firm has two options at date 3: the idea can be developed in a unit with access to firm-specific complementary assets, and the worker is paid a fixed wage; or, alternatively, the worker can develop the idea in a separate unit without access to complementary assets and be paid according to the profit of the unit (i.e., no transfer pricing and holdup problems). Proposition 2 shows that the firm will choose the first alternative optimally.

Proposition 2 Suppose the firm can offer the worker either a fixed wage using complementary assets or a profit-sharing contract not using complementary assets. The firm will maximize profit by offering a fixed-wage contract and letting the worker use complementary assets.

In light of the contributions of Klein et al. (1978) and Williamson (1979) it is not surprising that contracting problems in markets can lead to vertical integration and weaker incentives. In our model, it is the holdup problem associated with the noncontractibility of firm-specific complementary assets that makes integration optimal (ideas are developed inside the firm) and incentives weak.

Proposition 2 simplifies the analysis of the incomplete contracts case by letting us focus on fixed-wage contracts. Next, we will examine this case in more detail and focus on how wages, worker turnover, and litigation policy depend on the firm's level of firmspecific complementary assets. In Section 7.1, we extend the analysis by allowing the firm to observe the profitability of the new idea with some probability, and we show how this possibility leads to some profit sharing inside the firm.

\subsection{Equilibrium}

We now solve for the equilibrium when the firm cannot commit to litigation and wage policies at date 0 . To ease the exposition, we assume uniqueness of equilibrium for a given 
$(\theta, \phi)$. Proofs appear in Appendix A.

The worker's leaving decision: Because $\phi>0$, it will always be optimal for the firm to sue a leaving worker. Therefore the worker's utility is $B$ if staying with the firm and $x(1-\phi)$ if leaving. The worker leaves if $x$ exceeds the cutoff $z$, where $z=\frac{B}{(1-\phi)}$. Thus the best ideas tend to leave the firm.

The firm's wage offer: For a given $e$, the firm's profits equal:

$$
\Pi=\int_{-\infty}^{z-e}(\theta(e+\epsilon)-B) g(\epsilon) d \epsilon+\int_{z-e}^{\infty} \phi \theta(e+\epsilon) g(\epsilon) d \epsilon-F
$$

The first term captures the firm's gain from keeping the worker and developing the idea inside the firm. The second term captures the expected profits from suing a leaving worker. Substituting for $B=(1-\phi) z$ in equation (1) and differentiating with respect to $z$, we obtain the firm's marginal profits:

$$
\Pi_{z}=z(\theta-1)(1-\phi) g(z-e)-(1-\phi) G(z-e)
$$

The first term reflects the increase in profits from keeping higher worker types, and the second term reflects the larger wage bill to worker types that stay. Setting $\Pi_{z}=0$ defines implicitly the optimal $z$, denoted by $z^{*}$, with the second-order condition $\Pi_{z z}<0$. Because $\theta$ occurs only in the first term of equation (2), it follows that $z^{*}$ increases in $\theta$. Because $(1-\phi)$ occurs in both terms of equation $(2), z^{*}$ is independent of $\phi$. Thus the effects of a changed $\phi$ must occur via the worker's first-order condition.

The worker's effort decision: For a given $z$, the worker's expected utility equals:

$$
U=B G(z-e)+(1-\phi) \int_{z-e}^{\infty}(e+\epsilon) g(\epsilon) d \epsilon-c(e)
$$

The first term represents the worker's utility if staying $(x \leq z)$, and the latter term represents the worker's utility if he leaves $(x>z)$. Substituting for $B=(1-\phi) z$ in equation (3) and differentiating with respect to $e$, we obtain the worker's marginal utility:

$$
U_{e}=(1-\phi)(1-G(z-e))-c^{\prime}(e)
$$


The first term represents the marginal gain from effort while the second term reflects the marginal cost. Because $1-G\left(z-e^{*}\right)$ equals the probability that the agent starts up his own company, we see that the agent's motivation to exert effort stems from the possibility of becoming an entrepreneur. The optimal effort level, denoted by $e^{*}$, is defined implicitly by $U_{e}=0$. It follows from equation (4) that the worker will be more motivated if property rights are weak (low $\phi$ ) or if he expects a low wage offer (i.e., a low $z$ ). Because $\theta$ does not occur in equation (4), worker effort does not depend directly on $\theta$. Thus the effects of a changed $\theta$ must come via the firm's first-order condition. Equilibrium is a combination $\left(e^{*}, z^{*}\right)$ that solves equations (2) and (4) with equality.

Let us summarize the equilibrium with the following remark.

\section{Remark 1 In equilibrium,}

(i) effort is lower than in the complete contracts case,

(ii) turnover is positive,

(iii) the best ideas leave the firm.

To illustrate the equilibrium, consider Figure 2, which illustrates the worker's best effort response function $e^{*}(z)$ and the firm's best response function $z^{*}(e)$.

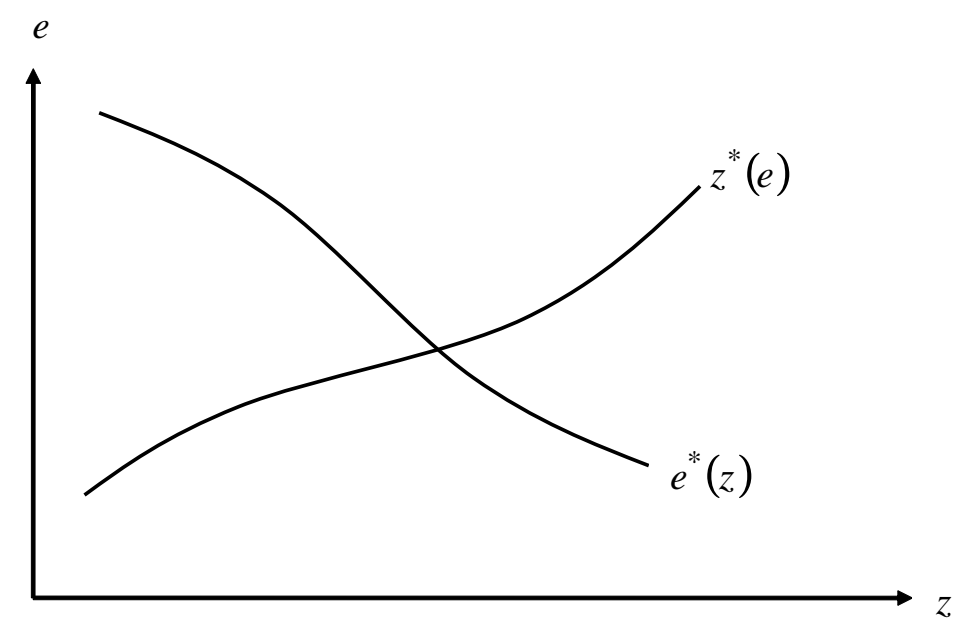

Figure 2: Equilibrium in the non-commitment case

The worker's best response function $e^{*}(z)$ slopes downward in $(z, e)$ space, because a higher expected wage offer means that the worker becomes less motivated. The firm's best response function $z^{*}(e)$ slopes upward in $(z, e)$ space, because a higher effort means 
that it will become more attractive to keep the marginal worker type. ${ }^{15}$ The unique equilibrium is given by the intersection of the two lines. Worker types with ideas whose value exceeds $z$ leave the firm.

In the following sections, we analyze how the equilibrium is affected by a change in the level of complementary assets and in the strength of property rights protection.

\subsection{Complementary assets}

Firms often hold assets that are important for developing new ideas. Potential complementary assets include existing patents, specialized production capacity, or co-workers with knowledge important for further development of the idea. In this section, we examine how these firm-specific complementary assets influence the firm's choice of policies for retaining and motivating the worker. We define turnover as the probability of the worker leaving the firm, i.e., $1-G(z-e)$.

Proposition 3 More firm-specific complementary assets (higher $\theta$ ) give

i) higher continuation wage,

ii) lower effort, and

iii) lower worker turnover.

Figure 3 illustrates how an increase in the amount of complementary assets changes the equilibrium outcome.

\footnotetext{
${ }^{15}$ Both of these statements follow from differentiating the first-order conditions implicitly.
} 


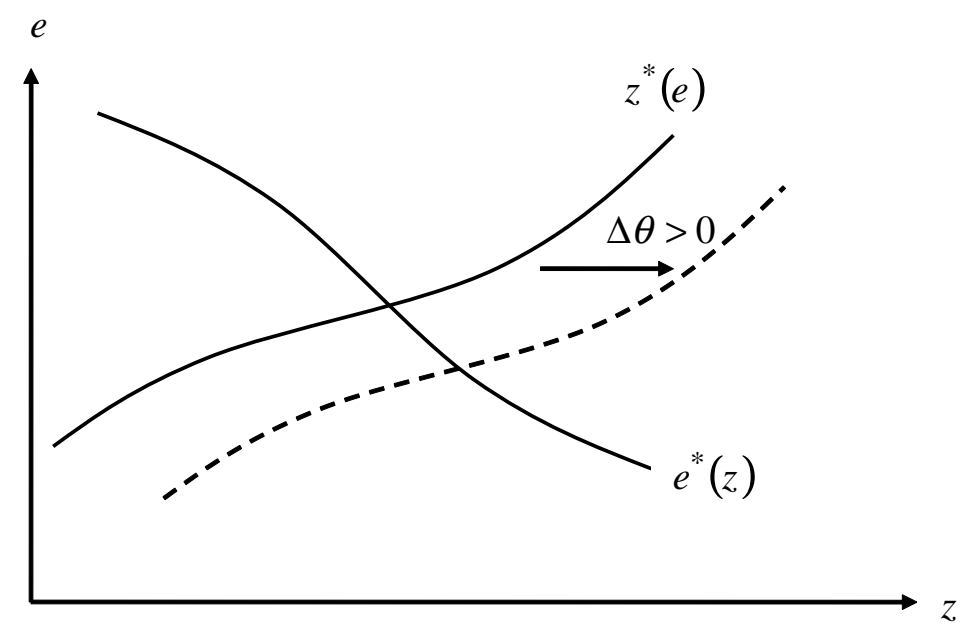

Figure 3: Effects of stronger firm-specific complementary assets.

When $\theta$ increases, the worker's best response function $e^{*}(z)$ is unaffected (the value of the entrepreneurial option is unchanged), whereas the firm's best response function $z^{*}(e)$ shifts to the right; for any level of effort, it becomes more beneficial for the firm to keep the marginal worker. Consequently, when $\theta$ increases, the firm raises its wage offer to keep more worker types. When the wage is raised, the entrepreneurship option becomes less attractive relative to staying on in the firm, and worker effort decreases. Both these effects pull in the direction of a reduced turnover rate.

\subsection{Intellectual property rights}

Merges (1999) and Stone (2002) argue that courts' enforcement of postemployment restraints varies from state to state and even from case to case. For example, courts differ in their interpretation of whether negative knowledge qualifies as a trade secret (Stone, 2002, p. 756) or more generally in their emphasis of the protection of firms' R\&D investments versus the protection of free worker mobility and the right to start up a new company. Alternatively, legal scholars argue that Massachusetts courts are more "pro-firm" while the California courts are "pro-employee" when they interpret noncompete clauses and other features of contract law (see Merges, 1999, and Hellmann, 2007). In this section, we examine how the strength of intellectual property rights, as captured by $\phi$, influences the firm's choice of policies for retaining and motivating workers. 
Proposition 4 Stronger intellectual property rights (increased $\phi$ ) give
i) lower continuation wage,
ii) lower worker effort, and
iii) higher turnover.

The effects from strengthened intellectual property rights are illustrated in Figure 4.

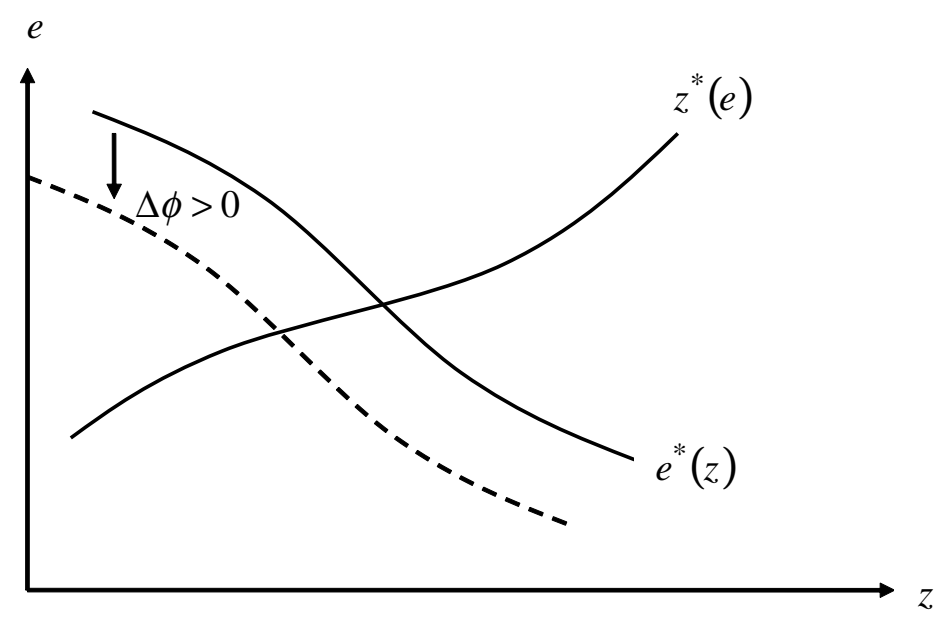

Figure 4: Effects from strengthened intellectual property protection.

When $\phi$ increases, the worker has weaker incentives to exert effort, because the entrepreneurial payoff is smaller. Hence $e^{*}(z)$ shifts downward. An increased $\phi$ makes it cheaper for the firm to keep the marginal worker, because the entrepreneurial option has become less attractive. At the same time, the worker's departure becomes less costly to the firm. These two effects cancel in equilibrium, and the $z^{*}(e)$ function stays fixed. Because $B=z(1-\phi)$, an increase in $\phi$ leads to a lower wage. There are two effects on the turnover rate $1-G(z-e)$. First, $z$ decreases, which in isolation leads to higher turnover. On the other hand, stronger intellectual property rights decrease effort, which (for a given $z$ ) leads to a lower turnover rate. In the proof of Proposition 4, we show that the second effect dominates.

Regarding welfare, we argue based on Proposition 4 that efficient intellectual property rights should balance the beneficial ex-ante effects from motivating workers against the negative ex-post effects on the use of complementary assets. Two features of the efficient $\phi$ can be noted. First, $\phi=1$ can never be strictly optimal. The reason is that if $\phi=1$ 
and the firm sues, no worker types will leave, and effort will be zero. When $\phi=1$, the marginal gain in effort from decreasing $\phi$ is therefore large while the marginal turnover cost is small. Second, $\phi=0$ cannot be optimal if $\theta$ is close to 1 . The intuition is that if $\phi=0$ and $\theta$ is close to 1 , the firm's profits must be negative, and the worker would not be employed in the first place. The welfare trade-off we identify stands in contrast with the view put forward by Merges (1999), who argues that strong employer protection should be implemented to encourage both the firm's R\&D investments and efficient expost use of innovations. The difference between our analysis and that of Merges (1999) is that we focus on the harmful ex-ante effects on employee motivation from stronger (firm) property rights protection. We also note that existing R\&D policy literature (see Scotchmer, 2004) typically argues that intellectual property rights should be strong when ex-ante effects (on firms' R\&D investments) are important relative to ex-post effects (on the use of innovations). Our analysis complements this literature by suggesting that intellectual property rights should be weak when the ex-ante effects (on worker initiative) are relatively important and strong when the ex-post effects (on the use of complementary assets) are important.

\section{Commitment}

In this section, we assume that the firm can commit to wage and suing policies at date 0 . Although we cannot characterize the solution as neatly as in the noncommitment case, we can generate some insights. Below we first characterize equilibrium and analyze the optimal suing decision. Then we analyze the comparative statics properties of equilibrium with respect to changes in $\theta$ and $\phi$ and compare this with the results of the noncommitment analysis.

\subsection{Equilibrium and the suing decision}

We now solve for the equilibrium when the firm can commit to litigation and wage policies at date 0. Proofs appear in Appendix B. ${ }^{16}$

\footnotetext{
${ }^{16}$ As the firm can always implement the same level of profits under commitment as under noncommitment, Proposition 2 will still hold, i.e., the firm maximizes profit by offering a fixed-wage contract and
} 
The worker's leaving decision: After $x$ has been learned by the worker and the firm has offered continuation wage $B$, the worker's utility is $B$ if staying, $x$ if leaving and not being sued by the firm, and $x(1-\phi)$ if leaving and being sued by the firm. Because the payoff from leaving increases in $x$ (independently of whether the firm sues or not), the worker leaves if $x$ is sufficiently high. A worker who expects not to be sued leaves if the value of the idea, $x$, is higher than $B$. On the other hand, a worker who expects to be sued leaves only if the value of the idea exceeds $B /(1-\phi)$. Thus, independently of the litigation decision, the best ideas tend to leave the firm.

The worker's effort decision: Let $I$ be an indicator function that equals 1 if the firm sues and 0 if not. For given wage and suing policies, the worker's expected utility is:

$$
U=B G(z-e)+(1-I \phi) \int_{z-e}^{\infty}(e+\epsilon) g(\epsilon) d \epsilon-c(e)
$$

The first term represents the worker's utility if staying $(x \leq z)$, and the latter term represents the worker's utility if he leaves $(x>z)$. It is the same expression as in the noncommitment case, equation (3), except that the suing decision by the firm is accommodated by the indicator function $I$. Recall that $z=B /(1-I \phi)$. Substituting for $B$ in equation (5) and differentiating with respect to $z$, we obtain:

$$
U_{e}=(1-I \phi)(1-G(z-e))-c^{\prime}(e)
$$

The first term represents the marginal gain from effort, while the second term reflects the marginal cost. Because $1-G(z-e)$ equals the probability that the worker leaves, we see that the agent's motivation to exert effort, as under noncommitment, stems from the possibility of becoming an entrepreneur. The optimal effort level, denoted by $e^{*}$, is defined implicitly by $U_{e}=0$. As under noncommitment, it follows from equation (6) that the worker will be more motivated if property rights are weak, or if he expects a low wage offer (i.e., $\left.e_{z}<0\right)$. It follows directly from equation (6) that,

Remark 2 Holding the wage fixed, worker effort is lower if the firm sues than if the firm

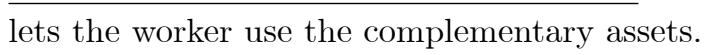


does not sue. Holding the suing decision fixed, worker effort decreases in the wage offer.

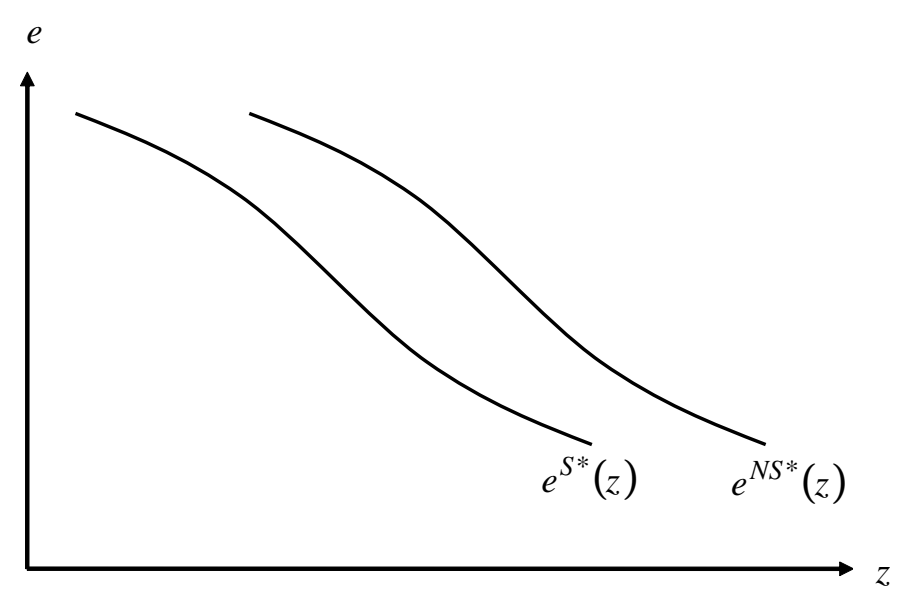

Figure 5: Effort with and without suing in the commitment case

Figure 5 illustrates the worker's optimal effort decision in the commitment case; $e^{S *}(z)$ is the worker's best response function if the firm sues and $e^{N S *}(z)$ is the worker's best response function if the firm does not sue. Under both suing regimes, a higher wage leads to a lower worker effort; both $e^{S *}(z)$ and $e^{N S *}(z)$ are downward sloping. For a given wage, worker effort is lower if the firm sues; $e^{S *}(z)$ lies to the south of $e^{N S *}(z)$. The firm's problem in the commitment case is to pick the point on $e^{S *}(z)$ and $e^{N S *}(z)$ that maximizes profits.

The firm's wage offer: The firm's profit equals:

$$
\Pi=\int_{-\infty}^{z-e(z)}[\theta(e(z)+\epsilon)-(1-I \phi) z] g(\epsilon) d \epsilon+\int_{z-e(z)}^{\infty} I \phi \theta(e(z)+\epsilon) g(\epsilon) d \epsilon-F .
$$

The first term captures the firm's gain from keeping the worker and developing ideas inside the firm. The second term captures the expected benefit from suing leaving worker types. The firm's profit, equation (7), is the same expression as in the noncommitment case, equation (1), except that $e$ is now a function of $z$ and the firm's suing decision is taken into account by the indicator function $I$. For the reduced form, we can write profits as a function $\Pi(z, e(z))$. The firm's marginal profits become:

$$
\frac{d \Pi}{d z}=\Pi_{z}+\Pi_{e} e_{z} .
$$


The first term is the direct effect of increasing $z$, which is the same as in the noncommitment case, and the second term accommodates the fact that changing $z$ will reduce worker effort. At the optimum, the firm sets $\frac{d \Pi}{d z}=0$ for either $I=0$ or $I=1$.

The second term of equation (8) is negative, and it follows from comparing equation (8) and equation (2) that the firm offers a lower wage in the commitment case than in the noncommitment case (conditional on the suing decision being the same in the two cases). The intuition is that increasing the wage has, relative to the noncommitment analysis, the additional effect of decreasing effort as depicted in Figure 5.

Recall that in the noncommitment analysis, it is always optimal for the firm to sue a leaving worker: there are no suing costs, and the firm may win in court. As illustrated in Figure 5, the commitment case gives the firm a genuine trade-off: the suing decision balances the positive effect of effort against the negative effect of letting more worker types leave.

Proposition 5 A firm protected strongly by intellectual property rights ( $\phi$ high) may not sue a leaving worker.

A firm protected strongly by intellectual property rights may increase profits by relinquishing its intellectual property rights and committing not to sue a leaving worker. The key to understanding this result is that a nonlitigation policy improves the worker's outside options and increases effort. Depending on the level of complementary assets inside the firm, the gain from increased effort may exceed the negative effect on profits from not litigating a leaving worker. Given this argument, one interpretation of Hewlett-Packard's personnel policy is that it was well protected by property rights and complementary assets - so well that litigating against leaving workers would seriously damage worker initiative.

We can also provide a condition under which it will be optimal for the firm to sue.

Proposition 6 A firm not protected by complementary assets $(\theta \approx 1)$ must sue a leaving worker to obtain positive profits.

If a firm not protected by complementary assets does not sue, only worker types with $x<B$ will stay on in the firm. This adverse selection problem leads to negative profits; hence the only way for such a firm to obtain positive profits is to sue a leaving worker. 


\subsection{Comparative statics}

Let us now discuss the comparative statics results under commitment, and compare them with the comparative statics results of the noncommitment case. Proposition 3 states that a firm holding more complementary assets will offer a higher wage, the worker exerts less effort, and turnover is lower. The same result holds under commitment if $c(e)$ is sufficiently convex.

Proposition 7 If $c^{\prime \prime}\left(e^{*}\right)>\left[1-c^{\prime}\left(e^{*}\right)\right] / z^{*}$, then having more complementary assets (higher $\theta)$ gives

i) higher continuation wage,

ii) lower effort, and

iii) lower worker turnover.

Independently of the firm's commitment power, having more complementary assets makes each worker idea more valuable, which makes it profitable to offer a higher wage and reduce worker turnover. However, in the commitment case there is the additional, opposite, effect: the firm can lower its wage offer in order to increase the value of the entrepreneurial option and thereby increase effort. The more complementary assets, the more important it is for the firm to stimulate effort, which strengthens the importance of this effect for the firm. Hence, in isolation this effect means that having more complementary assets leads to a lower wage. In the general case, either of these effects can dominate. The condition stated in Proposition 7 essentially puts a bound on this effect: if $c(e)$ is sufficiently convex, then the effort decision is sufficiently insensitive to incentives to ensure that Proposition 3 continues to hold in the commitment case. ${ }^{17}$

The comparative statics results on $\phi$ yield ambiguous results under commitment. For example, Proposition 4, part (ii), states that stronger intellectual property rights lead to lower effort. Just as in the noncommitment case, the direct effect on effort from an

\footnotetext{
${ }^{17}$ We have been unable to formulate a condition on the primitives of the model that ensures that Proposition 3 also holds in the commitment case. To ascertain that the condition in Proposition 7 is not vacuous, we have verified that it holds in examples. For example, let $g(\epsilon)$ be uniform on $\left[-\frac{1}{2}, \frac{1}{2}\right]$, $c(e)=1.01 e^{2}, \phi=.2$, and $\theta$ range between 1 and 2 .
} 
increased $\phi$ is negative, because the entrepreneurial option is less valuable. In the commitment case, there are two indirect effects that make the total effect on effort ambiguous. First, because the direct gain from litigating has increased for the firm, it may lower its wage offer, let some worker types leave, and then sue them in court. This effect pulls in the direction of increasing effort. Second, stronger intellectual property rights make the outside option less attractive to the worker, which makes it less costly to increase the wage in order keep more ideas (if $\phi$ is increased, it becomes cheaper to push the threshold $z$ upward by increasing $B$, because $z=B /(1-I \phi))$. This effect pulls in the direction of lowering effort. Thus, stronger intellectual property rights generate a negative direct effect on effort and indirect effects - via the firm's wage setting - that go in different directions, and the net effect could be either positive or negative. ${ }^{18}$

\section{Empirical implications}

Until recently, detailed evidence on the transition from employee to entrepreneur has been confined to convenient samples and case-level evidence where generalizations are hard to make (see Merges, 1999, for a discussion of interesting cases). Two new research projects improve on this situation. First, using a data set that contains information on about 1.5 million US inventors and their employers, Trajtenberg et al. (2006) develop an algorithm to trace inventors through time and across employers. Second, Hvide (2009) uses a large data set from Norway that contains information on both the performance of entrepreneurial ventures and characteristics of the entrepreneur's previous employers.

A central prediction of our model is that the workers leaving to start up their own company will be the workers with the best ideas. This prediction finds support both in Trajtenberg (2006) and in Hvide (2009). Trajtenberg (2006) finds that inventors with patents that score well on dimensions that are observable ex post but hard to observe ex ante (such as the patent being useful in a larger number of fields or receiving more citations) are more likely to move from their employer. Furthermore, Trajtenberg (2006) finds that employees who leave the firm produce better patents than employees who stay.

\footnotetext{
${ }^{18}$ We have generated numerical examples where both effort and turnover are nonmonotonic in $\phi$.
} 
These findings, as pointed out by Trajtenberg, suggest that inventors have better information about the expected impact of their intellectual capital than do their employers, and that the best ideas are more likely to leave. Hvide (2009) finds that entrepreneurs employed previously by firms that were less likely to have accurate information about idea quality (where employer size is taken as the main proxy for information accuracy) perform better as entrepreneurs. The evidence from both Hvide (2009) and Trajtenberg (2006) is consistent with our model, where asymmetric information about idea quality leads the workers with the most valuable ideas to leave the firm.

Another main prediction of the model, Proposition 3, says that the wage is higher and turnover is lower with more complementary assets $\theta$. The reason is that having more complementary assets increases the worker's value for the firm, which again leads the firm to increase the wage offer. With a higher wage, effort is reduced, because incentives become weaker. We are not aware of empirical studies that consider this prediction directly and therefore have to resort to indirect evidence. First, in some cases, we may associate the amount of complementary assets $(\theta)$ with firm characteristics such as size, leading larger firms to have stronger economies of scope. ${ }^{19}$ Proposition 3 then suggests that workers in small firms put in greater effort and create more start-up activities than do workers in large firms. This is consistent with the empirical regularities that larger firms have lower turnover (Oi, 1983, Even and MacPherson, 1996) and pay higher wages (e.g., Fox, 2004). Second, we can view $\theta$ alternatively as a measure of productivity for a given firm size. Consistent with Proposition 3, Groysberg et al. (2001) find that higherproductivity firms in the equity analyst industry have lower turnover. Regarding wages, Van Reenen (1996) finds that firms that experience faster technological progress have higher wage growth. ${ }^{20}$ Third, mergers and acquisitions, particularly in the technology

\footnotetext{
${ }^{19}$ Economies of scope are the purported motive behind many mergers and acquisitions. Such a motive would generate a positive link between firm size and economies of scope. The extent to which mergers do in fact create economies of scope (rather than, say, market power) is considered by a large body of literature, whose findings are not conclusive. For a recent contribution to this literature, see Gomes and Livdan (2004).

${ }^{20}$ One can also relate $\theta$ to industry maturity. Initially, firms are small, wages are low, and the start-up activities are plentiful. As the industry matures, concentration increases, and there are more complementary assets inside the firm, workers get better wage offers inside the firm but are less motivated, and fewer workers leave to start up their own businesses. This provides a simple argument for why entry rates are lower in mature industries. We are not aware of direct evidence relating to this question but
} 
sector, are motivated often by gaining economies of scope. Our prediction would be that after such mergers, wages should increase and turnover decrease. Conyon et al. (2004) find that wages do tend to increase following mergers. Brown and Medoff (1987) report a similar finding. Taken together, these empirical findings do not provide conclusive evidence in favor of Proposition 3 but do at least corroborate the hypotheses derived from it.

Legal scholars argue that legislation on employee inventions varies from state to state within the US (Merges, 1999). For example, the Massachusetts courts are more "pro-firm" while the Californian courts are "pro-employee" (see Hellmann, 2007, for references) when they interpret noncompete clauses and other features of contract law. Proposition 4 says that stronger intellectual property rights lead to lower effort. This result has resonance in Saxenian (1994), who argues that firms along Route 128 in Massachusetts have fared worse than their counterparts in Silicon Valley. In addition to geographic variation, the strength of property rights may vary across time or across industries (Cohen et al., 2000). For example, up to the $1980 \mathrm{~s}$, software innovations were difficult to patent in the US unless embedded in hardware such as mainframe computers or pizza ovens. Landmark court decisions in the mid-1990s improved the scope of patenting software dramatically (Cohen and Lemley, 2001). Such variation in property rights protection across industries or time may be explored in light of Proposition 4.

\section{$7 \quad$ Extensions}

In this section, we discuss two extensions of the basic model that will allows us to analyze profit sharing and out-of-court settlements. For tractability reasons, we confine ourselves to considering these two extensions for the noncommitment case.

\subsection{Profit sharing inside the firm}

Milgrom and Roberts (1992) report that Applied Materials Inc., a California-based producer of semiconductor equipment, offered employees who developed new products a per-

note that Long and Link (1983) find that firms in more-concentrated markets have lower turnover. 
centage of the resulting revenues. The physicist who led the team that developed one particularly successful product received more than $\$ 800,000$ in pay which exceeded the CEO's pay that year. This example illustrates that some firms are able to assess the value of new ideas and accordingly offer compensation. We now extend the model in a simple way to examine the effects of firms being able to assess the value of new ideas.

Assume that the firm observes with probability $p$ the value of the idea before the continuation wage contract is offered (after date 2 and before date 3 in Figure 1). ${ }^{21}$ Furthermore, we assume that the firm needs the worker to explore the idea even in the case where idea quality is revealed..$^{22}$ If not, the firm could offer a zero continuation wage and expropriate the idea from the worker.

If the firm observes $x$, the wage offer will be $(1-\phi) x$, and there will be no turnover, just as in the complete contracts case (Proposition 1). On the other hand, if the firm does not observe $x$, the firm's profits equal:

$$
\int_{-\infty}^{z-e}(\theta(e+\epsilon)-B) g(\epsilon) d \epsilon+\int_{z-e}^{\infty} \phi \theta(e+\epsilon) g(\epsilon) d \epsilon-F
$$

This is the same expression as in Section 4.1, and hence the optimal $z$ is given by the solution to equation $(2) .{ }^{23}$ For a given $z$, worker utility equals:

$$
U=p \int_{-\infty}^{\infty}(1-\phi)(e+\epsilon) g(\epsilon) d \epsilon+(1-p)\left[\int_{-\infty}^{z-e} z g(\epsilon) d \epsilon+\int_{z-e}^{\infty}(1-\phi)(e+\epsilon) g(\epsilon) d \epsilon\right]-c(e)
$$

The first term is the wage if the firm learns $x$, and the second term is the payoff if $x$ is not learned by the firm. For $p=1$, equation (10) reduces to the complete contracts case (Section 3), and for $p=0$, equation (10) reduces to the incomplete contracts case (Section 4). The worker's marginal utility equals:

$$
U_{e}=p(1-\phi)+(1-p)(1-\phi)[1-G(z-e)]-c^{\prime}(e)
$$

\footnotetext{
${ }^{21}$ Note that because the firm has profit-maximizing incentives to adjust the wage offer to match the worker's outside opportunity, it suffices that the firm observes the idea value. Outside verification is not needed.

${ }^{22}$ As pointed out by Merges (1999), employee innovations are often in an early stage or involve a high degree of noncodifiable know-how held by the specific employee alone.

${ }^{23}$ Note that the optimal $z$ will not be the same as in Section 4.1, because worker effort is a function of $p$.
} 
The first term is the marginal gain from effort when $x$ becomes observable, and the second term is the marginal gain from effort when $x$ does not become observable. The optimal effort, $e^{*}$, is defined implicitly by setting equation (11) equal to zero. Note that it follows from equation (11) that, all else being equal, effort increases in $p$. The following proposition shows that the effects of comparative statics on $\theta$ (Proposition 3) and $\phi$ (Proposition 4) are the same as in the noncommitment case.

Proposition 8 Suppose $0<p<1$. Then the following holds:

(i) more firm-specific complementary assets (higher $\theta$ ) give a higher wage, lower effort, and lower worker turnover, and

(ii) stronger intellectual property rights (increased $\phi$ ) give a lower wage, lower worker effort, and higher turnover.

The intuition for part (i) is that having more complementary assets does not have a direct effect on effort, while they give the firm stronger incentives to keep the marginal worker in the case when $x$ is not observed. (When $x$ is observed, the firm's incentives are not affected.) Thus the firm's wage offer increases in $\theta$, and effort decreases, as depicted in Figure 3. The intuition for part (ii) is that independently of whether $x$ is observed, the firm's wage offer decreases in $\phi$, and hence worker effort decreases.

Regarding the effects of a change in idea observability $p$, we have the following comparative statics result.

Proposition 9 Suppose that the firm observes directly the quality of the idea with probability $p$. As p increases,

(i) worker effort increases, and

(ii) turnover decreases.

The possibility of the idea value becoming observable to the firm incentivizes the worker and triggers higher effort and improved idea quality. Because ideas on average are better, the firm offers a higher wage also in the case where the idea quality is unobservable (as shown in Appendix C), which reduces the worker's incentives to put in effort. We 
show that this indirect negative effect on effort is smaller than the direct positive effect from increased $p .^{24}$

Trajtenberg (2006) finds that inventors with patents that score well on dimensions that are hard to observe ex ante (such as the patent being useful in a larger number of fields or receiving more citations) are more likely to leave their employer. Moreover, employers successfully preempt moves by inventors with patents on ideas that are "better" in observable ways. These findings are consistent with Proposition 9.

The firm's ability to monitor the worker and assess the ideas produced may vary with firm characteristics. Monitoring of workers can be particularly costly when the firm is larger, more decentralized, there is more noise in the business environment, and the firm has greater growth opportunities (Core and Guay, 2001, Demsetz and Lehn, 1985, Jensen and Meckling, 1992, and Smith and Watts, 1992). On the other hand, transparent and small firms may be in a better position to assess the quality of new worker ideas. From this argument, one would expect effort to be higher and turnover to be lower in smaller firms. $^{25}$

\subsection{Out-of-court settlements}

We have assumed that there are no costs associated with bringing a case to court, which implies that the firm always sues a leaving worker in the noncommitment analysis in Section 3. Introducing legal costs for the worker does not alter the results of Sections 3 or 4 , because the worker would never initiate a court case. Introducing legal costs for the firm modifies the noncommitment analysis of Section 3 in that the firm will not sue the worker if the expected idea value is low relative to suing costs. Firm suing costs will not alter the comparative statics results.

Here we introduce firm suing costs and focus on how such costs provide incentives for

\footnotetext{
${ }^{24}$ The analysis of profit sharing in the case where the firm commits to wage and suing policies is analytically complex, and we have been unable to verify whether Proposition 9 holds or not.

In the special case where the agent's outside option is constant (i.e., $\phi=1$ ) and the firm sues, results from Poblete \& Spulber (2009) apply. They show that if the hazard rate of $g(\epsilon)$ is decreasing, the optimal wage contract is a call option on output.

${ }^{25}$ The relationship between firm size and monitoring is unclear and needs to be examined further. For instance, Friebel \& Giannetti (2009) argue that small firms scrutinize new ideas less and acquire less information about new ideas before they choose to invest.
} 
the parties to reach an out-of-court agreement through negotiations. Suppose that after observing the worker leaving, the firm demands compensation $L$ from the worker. If the demand is accepted by the worker, the firm refrains from suing. If the offer is rejected, the worker and the firm engage in court. We consider again the noncommitment case and let $v$ be the firm's costs associated with suing a leaving worker. ${ }^{26}$

The equilibrium outcome splits the value of ideas into three intervals. The first interval consists of worker types with the poorest ideas. These worker types accept the continuation wage offered and stay inside the firm. The second interval consists of worker types with ideas of intermediate value. These leavers do not accept paying $L$ and are litigated against by the firm. The third interval consists of worker types with the best ideas. These worker types pay $L$ to the firm and are not litigated against.

The firm's profit function if the worker has left the firm equals:

$$
\left(1-F\left(\frac{L}{\phi}\right)\right) L+\int_{-\infty}^{\frac{L}{\phi}}(\phi \theta x-v) f(x) d x
$$

where $F($.$) and f($.$) represent the probability and density functions, respectively, of idea$ value for a worker that has left the firm. The first term of equation (12) represents the profit from out-of-court settlements, while the second term is the expected profit from suing worker types that reject $L$. The firm chooses $L$ in equation (12) to maximize profits. In choosing $L$, the firm balances the gain from higher compensation from accepting worker types and the loss because of the lower acceptance rate.

Observe that it follows from equation (12) that more complementary assets make the firm more inclined to set $L$ high and meet the worker in court. Having more complementary assets implies that there are larger gains for the firm in trying to win in court and develop the idea inside the firm. The commitment case is more complex analytically but preserves the structure in which the equilibrium outcome splits the value of ideas into three intervals.

\footnotetext{
${ }^{26}$ We do not consider the possibility that legal expenses are endogenous and determined by the parties' marginal incentives to influence the court outcome by investing in legal resources (Cooter \& Rubinfeld, 1989).
} 
Our analysis suggests that larger firms, having more complementary assets, litigate against leaving workers aggressively and are less willing to settle out of court than are smaller firms. Lerner (2004) collected data on all litigation cases for a sample of firms from Middlesex, Massachusetts (the borough in which the hi-tech area Route 128 is located). Consistent with our analysis, Lerner (2004) finds that larger firms are more involved with litigation cases involving intellectual property rights than are small firms. ${ }^{27}$

\section{Conclusion}

We have developed a theoretical framework to study how firm-specific complementary assets and intellectual property rights affect the management of knowledge workers. We have three main findings. First, firms protected weakly by complementary assets must sue in order to obtain positive profits. In contrast, firms protected strongly by property rights may not sue leaving workers in order to motivate effort. Second, firms with more complementary assets pay higher wages and have lower turnover, but such higher pay has a detrimental effect on worker initiative. Third, we suggest that the socially optimal intellectual property rights protection strikes the balance between the efficient use of complementary assets and worker initiative.

We see three areas of application for our work. First, our findings on the optimal litigation policy might be useful for firms deliberating which attitude to take vis-a -vis departing workers. Our analysis suggests a clear trade-off: more litigation gives the firm a larger piece of the cake if a worker leaves, but also results in less worker initiative and hence a smaller cake. Second, our results showing that stronger complementarities imply higher wages, less turnover, and less worker initiative give a set of hypotheses to test for in personnel data on R\&D-intensive firms. These predictions are not obvious; for example, the efficiency wage theory of Shapiro and Stiglitz (1984) predicts that higher wages should lead workers to exert more effort (because of the increased cost of being fired). Third, our results on the effects of property rights legislation may be of interest to policy makers who

\footnotetext{
${ }^{27}$ Our analysis suggests that the cases observed in court are intermediate in terms of value, while the higher-value cases are settled out of court. As Lerner's data set does not contain information on out-of-court settlements, this prediction is not testable in his data.
} 
aim to understand better the effects of changes in intellectual property rights legislation. One case that comes to mind is the current discussion in Europe on the appropriate patent protection for software innovations: we suggest that strengthened protection may reduce turnover costs but may also decrease the productivity of knowledge-work because of less motivated workers.

\section{References}

Aghion, P. and J. Tirole (1994) The Management of Innovation. Quarterly Journal of Economics, 113, 1185-1209.

Anton, J. and D. Yao (1994) Expropriations and Inventions: Appropriable Rents in the Absence of Property Rights. American Economic Review, 84, 190-209.

Anton, J. and D. Yao (1995) Start-ups, Spin-offs, and Internal Projects. Journal of Economics, Law, and Organization, 11, 362-78.

Anton, J. and D. Yao (2002) The Sale of Ideas: Strategic Disclosure, Property Rights and Contracting. Review of Economic Studies, 69, 513-531.

Anton, J. and D. Yao (2004) Little Patents and Big Secrets: Managing Intellectual Property. Rand Journal of Economics, 35, 1-22.

Bebchuk, L. A. (1984) Litigation and Settlement under Imperfect Information. Rand Journal of Economics, 15, 404-415.

Bhide, A. (2000) The Origin and Evolution of New Businesses. Oxford University Press.

Brown, C. C. and J. L. Medoff (1987) The Impact of Firm Acquisitions on Labor. NBER working paper 2273.

Cohen, J. and M. A. Lemley (2001) Patent Scope and Innovation in the Software Industry. California Law Review, 89, 1-57.

Cohen, W. M., R. P. Nelson, and J. P. Walsh (2000) Protecting their Intellectual Assets: Appropriability Conditions and Why U.S. Manufacturing Firms Patent (or Not). NBER working paper 7552 .

Conyon, M. J., S. Girma, S. Thompson, and P. W. Wright (2004) Do Wages Rise or Fall Following a Merger? Oxford Bulletin of Economics and Statistics, 66, 847-62. 
Cooper, A. (1985) The Role of Incubator Organizations in the Founding of Growthoriented Firms. Journal of Business Venturing, 1, 75-86.

Cooter, R. D. and D. L. Rubinfeld (1989) Economic Analysis of Legal Disputes. Journal of Economic Literature, 27, 1067-97.

Core, J. E. and W. R. Guay (2001) Stock Option Plans for Non-executive Employees, Journal of Financial Economics, 61, 253-287.

Crawford, V. P. (1988) Long-term Relationships Governed by Short-term Contracts, American Economic Review, 78, 485-499.

Delaney, E. J. (1993) Technology Search and Firm Bounds in Biotechnology: New Firms as Agents of Change. Growth and Change, 24, 206.

Demsetz, H. and K. Lehn (1985) The Structure of Corporate Ownership: Causes and Consequences. Journal of Political Economy, 93, 1155-1177.

Even, W. and D. MacPherson (1996) Employer Size and Labor Turnover: The Role of Pensions. Industrial \& Labor Relations Review, 49, 707-28.

Fisk, C. L. (2001) Working Knowledge: Trade Secrets, Restrictive Covenants in Employment, and the Rise of Corporate Intellectual Property 1800-1920. Hastings Law Journal, 52, 441-528.

Fox, J. (2004) Employer Size Wage Gap Revisited. Mimeo, University of Chicago, Economics Department.

Friebel, G. and M. Giannetti (2009) Fighting for Talent: Risk-taking, Corporate Volatility, and Organizational Change. Economic Journal, 119, 1344-1373.

Gambardella, A. and C. Panico (2008) Designing Governance Mechanisms for Knowledgeintensive Activities. Mimeo, Boccioni University.

Glynn, J. and P. Mukherjee (2003) Cadence vs. Avant! Case E-61A/B, Stanford Graduate School of Business.

Gomes, J. and D. Livdan (2004) Optimal Diversification: Reconciling Theory and Evidence. Journal of Finance, 59, 507-35.

Gompers, P. A. and J. Lerner (1998) The Determinants of Corporate Venture Capital Success: Organizational Structure, Incentives, and Complementarities. NBER working paper 6725 .

Grossmann, S. and O. Hart (1986) The Cost and Benefits of Ownership: A Theory of 
Vertical and Lateral Integration, Journal of Political Economy, 94, 691-719.

Groysberg, B., A. Nanda, and M. J. Prats (2001) Entrepreneurship among Knowledge Workers: Evidence from Equity Analyst Market. Harvard Business School Working Paper No. 02011.

Hart O. and J. Moore (1990) Property Rights and the Theory of the Firm, Journal of Political Economy, 1119-1158.

Hellmann, T. (2007) When Do Employees Become Entrepreneurs? Management Science, 53, 919-933.

Hvide, H. K. (2009) Firm Size and the Quality of Entrepreneurs. Economic Journal, 119, 1010-35.

Jensen, M. and W. Meckling (1992) Specific and General Knowledge, and Organizational Structure. In: Werin, L. and H. Wijkander (Eds.) Contract Economics. Basil Blackford: Oxford, 251-274.

Kim, J. and G. Marschke (2005) Labor Mobility of Scientists, Technological Diffusion, and the Firm's Patenting Decision. Rand Journal of Economics, 36, 298-317.

Klein, B., R. Crawford, and A. Alchian (1978) Vertical integration, Appropriable Rents, and the Competitive Contracting Process. Journal of Law and Economics, 21, $297-326$.

Lanjouw, J. O. and J. Lerner (1998) The Enforcement of Intellectual Property Rights: A Survey of the Empirical Literature. Annales d'Economie et Statistique, 49-50, 223-46.

Lemley, M. A. and C. Shapiro (2005) Probabilistic Patents. Journal of Economic Perspectives, 19, 75-98.

Lerner, J. (2004) The Choice of Intellectual Property Protection: Evidence from Civil Litigation. Mimeo, Harvard Business School.

Lewis, T. R. and D. Yao (2003) Innovation, Knowledge Flow, and Worker Mobility. Mimeo, Duke University.

Long, J. E. and A. N. Link (1983) The Impact of Market Structure on Wages, Fringe Benefits, and Turnover. Industrial \& Labor Relations Review, 36, 239-250.

Lowry, S. (1988) Inevitable Disclosure Trade Secret Disputes: Dissolution of Concurrent Property Interests. Stanford Law Review, 519.

Mailath, G. J. and L. Samuelson (2006) Repeated Games and Reputations: Long-run 
Relationships. Oxford University Press.

Mansfield, E. (1986) Patents and Innovation: An Empirical Study. Management Science, $32,173-81$.

Merges, R. P. (1999) The Law and Economics of Employee Innovations. Harvard Journal of Law $\&$ Technology, 13, 1-55.

Milgrom, P. and J. Roberts (1992) Economics, Organization and Management. Englewood Cliffs: Prentice-Hall.

Motta, M. and T. Rønde (2003) Trade Secret Laws, Labor Mobility. CEBR discussion paper 2003-17.

Møen, J. (2005) Is Mobility of Technical Personnel a Source of R\&D Spillovers? Journal of Labor Economics, 23, 81-114.

Neef, D. (1999) Rethinking Economics in the Knowledge-based Economy. In: Neef, D., G. A. Siesfeld, and J. Cefola (Eds.) The Economic Impact of Knowledge. 3, 4. Butterworth Press.

Oi, W. (1983) The Fixed Employment Costs of Specialized Labor. In: J. E. Triplett (Ed.) The Measurement of Labor Costs. Chicago: University of Chicago Press.

Oyer, P. and S. Schaefer (2005) Why Do Some Firms Give Stock Options to All Employees? An Empirical Examination of Alternative Theories. Journal of Financial Economics, 76, 99-133.

Packard, D. (1995) The HP Way: How Bill Hewlett and I Built Our Company. Reed Business Information, Inc.

Pakes, A. and S. Nitzan (1983) Optimum Contracts for Research Personnel, Research Employment, and the Establishment of "Rival" Enterprises. Journal of Labor Economics, $1,345-365$.

Poblete, J. and D. Spulber (2009) The Limited Liability Agency Model with Moral Hazard. Mimeo, London School of Economics.

Priest, G. and B. Klein (1984) The Selection of Disputes for Litigation. Journal of Legal Studies, 8, 1-56.

Reinganum, J. F. and L. L. Wilde (1986) Settlement, Litigation, and the Allocation of Litigation Costs. Rand Journal of Economics, 17, 577-566.

Roberts, J. (2004) The Modern Firm: Organizational Design for Performance and 
Growth. Clarendon Lectures in Management Studies. New York: Oxford University Press.

Saxenian, A. (1994) Regional Advantage: Culture and Competition in Silicon Valley and Route 128. Cambridge: Harvard University Press.

Scotchmer, S. (2004) Innovation and Incentives. MIT Press.

Shapiro, C. and J. E. Stiglitz (1984) Equilibrium Unemployment as a Worker Discipline Device. American Economic Review, 74, 433-44.

Siegelman, P. and J. Waldfogel (1996) A Taxonomy of Disputes: New Evidence through the Prism of the Priest and Klein Model. Working paper, Yale University.

Smith, C. and R. Watts (1992) The Investment Opportunity Set and Corporate Financing, Dividends, and Compensation Policies. Journal of Financial Economics, 32, 263-292.

Stone, K. V. W. (2002) Knowledge at Work: Disputes Over the Ownership of Human Capital in the Changing Workplace. Connecticut Law Review, 34, 721-63.

Subramanian, N. (2005) The Economics of Intrapreneurial Innovation. Journal of Economic Behavior and Organization, 58, 487-510.

Teece, D. J. (1986) Profiting from Technological Innovation: Implications for Integration, Collaboration, Licensing and Public Policy. Research Policy, 15, 285-305.

Trajtenberg, M. (2006) The Mobility of Inventors and the Productivity of Research. Slides presented at European Science days, Steyr, Austria, in July 2006.

Trajtenberg, M., G. Shiff, and R. Melamed. (2006) The "Names Game": Harnessing Inventors' Patent Data for Economic Research. NBER working paper 12479.

Van Reenen, J. (1996) The Creation and Capture of Rents: Wages and Innovation in a Panel of U.K. Companies. Quarterly Journal of Economics, 111, 195-226.

Williamson, O. E. (1975) Markets and Hierarchies. New York: Free Press.

Williamson, O. E. (1979) Transactions-cost Economics: the Governance of Contractual Relations. Journal of Law and Economics, 22, 233-62. 


\section{Appendix A. Proofs of Propositions 1-4}

Proof of Proposition 1: We solve the game backwards. The worker leaves if $B(x)<$ $(1-\phi) x$. It is therefore optimal for the firm to offer either $B=0$ or $B=(1-\phi) x$. An offer $B>(1-\phi) x$ would be wasting profits; an offer $B$ such that $0<B<(1-\phi) x$ would be rejected by the worker. If $B=0$, the worker leaves, because $(1-\phi) x>0$. It will be optimal for the firm to sue, and expected profits are $\theta \phi x$. If $B=(1-\phi) x$, the worker stays, and profits equal $\theta x-(1-\phi) x=(\theta-1+\phi) x$. However, $\theta-1+\phi>\theta \phi$ because $\theta>1$ and $\phi<1$, and therefore expected profits are higher from offering $B=(1-\phi) x$ than from offering $B=0$. It follows that under complete contracts there will be no turnover and profits will equal $(\theta-1+\phi) x$. Proof of Proposition 2: First consider the case where the firm invites the worker to develop the idea inside the firm in a separate unit without access to complementary assets and pays the worker as a function of $x$. The analysis is analogous to the complete contracts case: the firm offers the worker a wage equal to the outside option, i.e., $B(x)=(1-\phi) x$, the worker stays, and expected profits equal $\phi E(x)$. Now consider the case where complementary assets are employed, but only a fixed-wage contract is feasible. Suppose that the firm offers $B=0$ and sues all leaving worker types. Expected profits are $\theta \phi E[x]$, which exceeds the profit given that the worker is organized as a standalone unit, i.e., $\phi E[x]$. We have thereby shown that the firm prefers to offer a fixed-wage contract if contracting on firm-specific complementary assets is infeasible at date 3 .

Proof of Remark 1: Part (i): Under complete contracts, the first-order condition of the worker is $U_{e}=(1-\phi)-c^{\prime}(e)=0$; under incomplete contracts, the first-order condition is $(1-\phi)(1-G(z-e))-c^{\prime}(e)=0$. Because $G(z-e)>0$ and $c^{\prime \prime}(e)>0$, equilibrium effort is lower under incomplete contracts. Parts (ii) and (iii): As shown at the start of Section 4.1, worker types with $x>z$ leave the firm. That $z$ is finite follows directly from equation (2).

Proof of Proposition 3 and Proposition 4: For the reduced form, we can suppress 
$B$ and write the two first-order conditions (2) and (4) as:

$$
\begin{aligned}
\Pi_{z}(z, e, \phi, \theta) & =0 \\
U_{e}(e, z, \phi) & =0
\end{aligned}
$$

The solution to this system defines the equilibrium values of $e$ and $z$. Define the turnover rate as $T$, where $T=1-G(z-e)$. We now analyze the effect of a change in $\theta$ or $\phi$ on the equilibrium $e, z$, and $T$. Totally differentiate (13) to obtain:

$$
\begin{aligned}
\Pi_{z z} d z+\Pi_{z e} d e+\Pi_{z \phi} d \phi+\Pi_{z \theta} d \theta & =0 \\
U_{e e} d e+U_{e z} d z+U_{e \phi} d \phi & =0 .
\end{aligned}
$$

Note that it follows from (2) that $\Pi_{z \phi}=0$ at equilibrium. The solution to (14) becomes:

$$
\begin{aligned}
& \frac{d e}{d \theta}=-U_{e z} \Pi_{z \theta} / D, \frac{d z}{d \theta}=\Pi_{z \theta} U_{e e} / D \\
& \frac{d e}{d \phi}=\Pi_{z z} U_{e \phi} / D, \frac{d z}{d \phi}=-\Pi_{z e} U_{e \phi} / D
\end{aligned}
$$

where $D=\Pi_{z e} U_{e z}-\Pi_{z z} U_{e e}$. Let us evaluate the partials. Differentiating $U_{e}$ from equation (4) gives:

$$
\begin{aligned}
& U_{e \phi}=-(1-G(z-e))<0, \\
& U_{e e}=(1-\phi) g(z-e)-c^{\prime \prime}(e)<0 \text { (second-order condition for optimal effort), } \\
& U_{e z}=-(1-\phi) g(z-e)<0 .
\end{aligned}
$$

Note that $U_{e e}=-U_{e z}-c^{\prime \prime}(e)$. Now consider the firm's partials. Differentiating $\Pi_{z}$ from (2) we have:

$$
\begin{aligned}
& \Pi_{z z}<0 \text { (by the firm's second-order condition), } \\
& \Pi_{z e}=-\Pi_{z z}+(\theta-1)(1-\phi) g(z-e)>0 \\
& \Pi_{z \theta}=(1-\phi) z g(z-e)>0 .
\end{aligned}
$$


It follows from (16) and (17) that $D=\Pi_{z e} U_{e z}-\Pi_{z z} U_{e e}<0$. Now return to (15). Using (16) and (17), we can sign the expressions in equation (15) as:

$$
\begin{aligned}
& \frac{d e}{d \theta}<0, \frac{d z}{d \theta}>0 \\
& \frac{d e}{d \phi}<0 ., \frac{d z}{d \phi}<0
\end{aligned}
$$

That proves Proposition 3, parts (i) and (ii), and Proposition 4, parts (i) and (ii). We now prove Proposition 3, part (iii), and Proposition 4, part (iii). Recall that $T=(1-G(z-e))$. Therefore:

$$
\frac{d T}{d \theta}=g(z-e)\left(\frac{d e}{d \theta}-\frac{d z}{d \theta}\right)
$$

Substitute (15) into (19) using $U_{e e}=-U_{e z}-c^{\prime \prime}(e)$ to obtain:

$$
\begin{aligned}
\frac{d T}{d \theta} & =\left(-U_{e z} \Pi_{z \theta}-\Pi_{z \theta} U_{e e}\right) / D \\
& =-\Pi_{z \theta}\left(U_{e e}+U_{e z}\right) / D<0
\end{aligned}
$$

That proves Proposition 3, part (iii). Moving to the effect of a changed $\phi$ we have:

$$
\begin{aligned}
\frac{d T}{d \phi} & =g(z-e)\left(\frac{d e}{d \phi}-\frac{d z}{d \phi}\right) \\
& =g(z-e)\left(\Pi_{z z} U_{e \phi}--\Pi_{z e} U_{e \phi}\right) / D \\
& =g(z-e) U_{e \phi}\left(\Pi_{z z}+\Pi_{z e}\right) / D \\
& =g(z-e) U_{e \phi}(\theta-1)(1-\phi) g(z-e) / D>0 .
\end{aligned}
$$

That proves Proposition 4, part (iii). 


\section{Appendix B. Proofs for the commitment case}

In this appendix, we prove Proposition 5, Proposition 6, and Proposition 7. Proof of Proposition 5: We show that if the firm does not sue and $\theta=1$, the firm's profits are negative. First, note that if the firm does not sue, then $z=B$. For $\theta=1$, the profits therefore equal $\int_{-\infty}^{B-e}(e+\epsilon-B) g(\epsilon) d \epsilon$. This expression is negative, because $e+\epsilon-B<0$ for any $\epsilon<B-e$. By continuity, the firm's profits are also negative for $\theta$ close to 1 .

Proof of Proposition 6: It suffices to construct an example where suing leads to less profit than does not suing. Let $g(\epsilon)$ be distributed uniformly on $\left[-\frac{1}{2}, \frac{1}{2}\right]$ and let $c(e)=\frac{\gamma}{2} e^{2}$, where $\gamma>0$. Expected utility equals:

$$
U=\int_{-\frac{1}{2}}^{\frac{B}{1-\phi}-e} B g(\epsilon) d \epsilon+\int_{\frac{B}{1-\phi}-e}^{\frac{1}{2}}(1-\phi)(\epsilon+e) g(\epsilon) d \epsilon-c(e) .
$$

By differentiating with respect to $e$ and solving, we have the unique interior solution:

$$
e^{*}(B)=\frac{1}{s}\left(B+\frac{1}{2} \phi-\frac{1}{2}\right)
$$

where $s=1-\phi-\gamma$, and $s<0$ by the worker's second-order condition. Expected profits equal:

$$
\Pi=\int_{-\frac{1}{2}}^{\frac{B}{1-\phi}-e^{*}(B)}\left(\theta\left(e^{*}(B)+\epsilon\right)-B\right) g(\epsilon) d \epsilon+\int_{\frac{B}{1-\phi}-e^{*}(B)}^{\frac{1}{2}} \phi \theta\left(e^{*}(B)+\epsilon\right) g(\epsilon) d \epsilon .
$$

The firm maximizes $\Pi$ with respect to $B$, taking into account the negative impact of $B$ on $e$. Differentiating (24) with respect to $B$ and solving, we have the unique interior solution:

$$
B^{*}=(1-\phi) \frac{\left(\theta \gamma-3 \gamma-4 \phi-2 \theta+2 \theta \phi+3 \gamma \phi+\theta \gamma \phi+\gamma^{2}+2 \phi^{2}+2\right)}{2 \gamma(\theta \gamma-2 \gamma-2 \phi-2 \theta+2 \theta \phi+2)}
$$

From the firm's second-order condition, the denominator is negative. To ensure that $B^{*} \geq 0$, we require the numerator of $(25)$ to be negative. By substituting $e^{*}$ from $(23)$ and $B^{*}$ from (25) into the profit function (24), we obtain: 
$\Pi=(1-\phi) \frac{\theta^{2}\left(4 \gamma-\gamma^{2}-4\right)+2 \theta\left(\gamma^{2}-4 \phi-2 \gamma \phi-4 \gamma+4\right)+4 \gamma+8 \phi-4 \gamma \phi-\gamma^{2}-4 \phi^{2}-4}{8 \gamma(\theta \gamma-2 \gamma-2 \phi-2 \theta+2 \theta \phi+2)}$.

Observe that if $\phi=1$, suing yields profits equal to zero while not suing (identical to $\phi=0)$ yields profits equal to:

$$
\frac{(\gamma-2)^{2}(\theta-1)^{2}}{8 \gamma(2 \gamma+2 \theta-\theta \gamma-2)}
$$

This expression is positive if the second-order condition of the firm's profit maximization problem holds. Hence for $\phi=1$, the profits are greater if the firm does not sue than if it sues. That completes the proof. Note that by the continuity of $\Pi$ from equation (26), there exists a constant $k>0$ such that the profits from not suing are larger than the profits from suing for $\phi \in(k, 1]$.

Proof of Proposition 7: We start out by proving (i) and (ii). For part (i), note that $\frac{d z^{*}}{d \theta}>0$ implies $\frac{d B^{*}}{d \theta}>0$, because $B=z(1-I \phi)$. For part (ii), note that $\theta$ does not enter (6), which implies that $e_{z \theta}=0$. Therefore the effects on $e$ from a change in $\theta$ must operate via $z$, and to show that $\frac{d e^{*}}{d \theta}>0$, it is sufficient and necessary to show that $\frac{d z^{*}}{d \theta}<0$. Hence to prove part (i) and part (ii) of Proposition 7 we need to show that $c^{\prime \prime}\left(e^{*}\right)>\left[1-c^{\prime}\left(e^{*}\right)\right] / z^{*}$ implies $\frac{d z^{*}}{d \theta}>0$. By using the implicit function theorem on $(8)$, we have that:

$$
\frac{d z^{*}}{d \theta}=-\frac{d^{2} \Pi}{d z d \theta} / \frac{d^{2} \Pi}{d z^{2}}
$$

The denominator is always negative by the second-order condition of the firm's maximization problem. To evaluate the numerator, $\frac{d^{2} \Pi}{d z d \theta}$, we can differentiate (8) with respect to $\theta$ to obtain (we drop the ${ }^{*}$ notation):

$$
\frac{d^{2} \Pi}{d z d \theta}=z(1-I \phi) g(z-e)-[z(1-I \phi) g(z-e)-(1-I \phi) G(z-e)-I \phi] e_{z}
$$

Because $\frac{d e}{d z}=\frac{(1-I \phi) g(z-e)}{(1-I \phi) g(z-e)-c^{\prime \prime}(e)}$ from the worker's first order condition (6), this 
expression simplifies to:

$$
\begin{aligned}
\frac{d^{2} \Pi}{d z d \theta}= & z(1-I \phi) g(z-e) \\
& +[-z(1-I \phi) g(z-e)+G(z-e)(1-I \phi)+I \phi] \frac{(1-I \phi) g(z-e)}{(1-I \phi) g(z-e)-c^{\prime \prime}(e)} \\
= & \frac{(1-I \phi) g(z-e)\left[-z c^{\prime \prime}(e)+G(z-e)(1-I \phi)+I \phi\right]}{(1-I \phi) g(z-e)-c^{\prime \prime}(e)} .
\end{aligned}
$$

The denominator is negative by the worker's second-order condition, and therefore $\operatorname{sgn}\left(\frac{d^{2} \Pi^{S}}{d z d \theta}\right)=$ $-\operatorname{sgn}\left[-z c^{\prime \prime}(e)+G(z-e)(1-I \phi)+I \phi\right]$. Because $G(z-e)(1-I \phi)+I \phi=1-c^{\prime}(e)$ from the worker's first-order condition, we can conclude that the following condition ensures that $\frac{d z}{d \theta}>0$ :

$$
c^{\prime \prime}(e)>\left[1-c^{\prime}(e)\right] / z .
$$

Hence $\frac{d z}{d \theta}>0$ if (31) holds. That proves part (i) and part (ii). To prove (iii), recall that $T=1-G(z-e)$. Because $\frac{d z}{d \theta}>0$ and $\frac{d e}{d \theta}<0$ if (31) holds, part (iii) follows immediately.

\section{Appendix C: Profit sharing}

\section{Proof of Proposition 8:}

In the case where the firm observes $x$, the firm's wage offer equals $(1-\phi) x$ and there is no turnover. In the case where the firm does not observe $x$, the equilibrium can be expressed in reduced form as:

$$
\begin{aligned}
\Pi_{z}(z, e, \theta) & =0, \\
U_{e}(e, z, \phi, p) & =0 .
\end{aligned}
$$

The solution to this system gives the equilibrium values of $z$ and $e$. Note that, as in the noncommitment case, $\Pi_{z}(z, e, \theta)$ does not depend upon $\phi$, and $U_{e}$ does not depend upon 
$\theta$. Totally differentiating the system (32) gives:

$$
\begin{aligned}
\Pi_{z z} d z+\Pi_{z e} d e+\Pi_{z \phi} d \phi+\Pi_{z \theta} d \theta & =0 \\
U_{e e} d e+U_{e z} d z+U_{e \phi} d \phi & =0 .
\end{aligned}
$$

In reduced form, this is the same system of equations as in the noncommitment case. The proof of Proposition 8, part (i), follows from the same procedure as the proof of Proposition 3 and Proposition 4, and is omitted. Let us sketch the proof of Proposition 8, part (ii). First note that if $x$ is not observed by the firm, a change in $\phi$ will not affect the firm's wage offer; the only effect will be to lower worker effort, as in the noncommitment analysis of Section 3. If, on the other hand, $x$ is observed, a higher $\phi$ implies that the firm will lower the wage offer. Both the direct effect and the indirect effect (on the firm's expected wage offer) of an increased $\phi$ will reduce worker effort. That worker turnover decreases in $\phi$ follows from the same argument as in the proof of Proposition 4.

\section{Proof of Proposition 9:}

We start out by proving part (i). First note that in the case where the firm observes $x$, the wage offer will not depend on $p$. In the case where the firm does not observe $x$, the equilibrium $e$ and $z$ are given by (2) and (11). We can write the equilibrium in reduced form as:

$$
\begin{aligned}
\Pi_{z}(z, e) & =0, \\
U_{e}(e, z, p) & =0 .
\end{aligned}
$$

Totally differentiate (34) to obtain:

$$
\begin{aligned}
\Pi_{z z} d z+\Pi_{z e} d e & =0 \\
U_{e e} d e+U_{e z} d z+U_{e p} d p & =0 .
\end{aligned}
$$

Solving (35), we obtain:

$$
\frac{d e}{d p}=U_{e p} \Pi_{z z} / D
$$


where $D=\Pi_{z e} U_{e z}-\Pi_{z z} U_{e e}$. Let us now evaluate the partials. Differentiate $U_{e}$ from equation (11) to obtain:

$$
\begin{aligned}
& U_{e p}=(1-\phi) G(z-e)>0, \\
& U_{e e}=(1-p)(1-\phi) g(z-e)-c^{\prime \prime}(e)<0 \text { (second-order condition for optimal effort), } \\
& U_{e z}=-(1-p)(1-\phi) g(z-e)<0 .
\end{aligned}
$$

Note that $U_{e e}=-U_{e z}-c^{\prime \prime}(e)$. The partials for the firm when it does not observe $x$ are given by (17), i.e.,

$$
\begin{aligned}
& \Pi_{z z}<0 \text { (by the firm's second-order condition), } \\
& \Pi_{z e}=-\Pi_{z z}+(\theta-1)(1-\phi) g(z-e)>0 .
\end{aligned}
$$

Hence $D<0$ and $\frac{d e}{d p}>0$.

We now prove part (ii) for turnover. When $x$ is observed the turnover is zero, and when $x$ is not observed the turnover is $1-G(z-e)$. Hence expected turnover equals:

$$
T=(1-p)(1-G(z-e))
$$

Differentiating with respect to $p$ we obtain:

$$
\frac{d T}{d p}=-(1-G(z-e))+(1-p)\left(\frac{d e}{d p}-\frac{d z}{d p}\right)
$$

The first term is negative. To evaluate the second term, we need to evaluate $\frac{d e}{d p}-\frac{d z}{d p}$. Solving (35) we find that $\frac{d z}{d p}=-U_{e p} \Pi_{z e} / D>0$. Therefore:

$$
\begin{aligned}
\frac{d e}{d p}-\frac{d z}{d p} & =U_{e p} \Pi_{z z} / D+U_{e p} \Pi_{z e} / D \\
& =\left[\Pi_{z z}+\Pi_{z e}\right] U_{e p} / D \\
& =[(\theta-1)(1-\phi) g(z-e)] U_{e p} / D<0
\end{aligned}
$$


It follows immediately from (40) that $\frac{d T}{d p}<0$. Finally note that $\frac{d z}{d p}>0$ implies that $\frac{d B}{d p}>0$, because $B=z(1-\phi)$. 